\title{
Epstein-Barr virus induced sickle hepatopathy
}

\author{
Alison Towerman ${ }^{1}$, David Wilson ${ }^{1}$, and Monica Hulbert ${ }^{1}$ \\ ${ }^{1}$ Washington University in Saint Louis School of Medicine
}

February 12, 2021

\begin{abstract}
Sickle hepatopathy comprises a spectrum of disorders that vary in severity. Intravascular sickling and sinusoidal occlusion are the principal drivers of sickle hepatopathy, but infection or autoimmunity may act as triggers. We describe two cases of acute sickle hepatopathy initiated by primary Epstein-Barr virus (EBV) infection, a previously unreported association. The first case entailed a 14-year-old girl with hemoglobin SC (HbSC) disease who developed hepatic sequestration crisis that responded to a simple transfusion of erythrocytes. The second case was that of a 16-year-old boy with HbSC disease who experienced life-threatening intrahepatic cholestasis with multi-organ failure.
\end{abstract}

\section{Introduction}

Sickle hepatopathy of childhood encompasses a group of disorders ranging in severity from mild liver pain to multi-organ failure (Table 1). ${ }^{1-6}$ These diverse clinical manifestations are thought to reflect varying degrees of erythrocyte sickling, Kupffer cell hyperplasia, sinusoidal obstruction, hepatocyte ischemia, and intracanalicular cholestasis. ${ }^{2}, 5,7$ Sickle hepatopathy can arise spontaneously or may be triggered by infection or autoimmune diseases. ${ }^{1,5,8,9}$ Here, we describe two cases of acute sickle cell hepatopathy caused by Epstein-Barr virus (EBV), a novel association.

\section{Results}

\section{Patient 1}

A 14-year-old girl with hemoglobin SC (HbSC) disease and a history of two to three hospitalizations per year for vaso-occlusive episodes presented with fever and pain in her back, chest, and legs. There was no lymphadenopathy, pharyngitis, or hepatomegaly. White blood cell (WBC) count was $12 \times 10^{3} / \mu \mathrm{L}$, with numerous atypical lymphocytes $\left(1.2 \times 10^{3} / \mu \mathrm{L}\right)$, and $\mathrm{Hb}$ was slightly lower than her baseline of $10-10.5$ $\mathrm{g} / \mathrm{dL}$. Nasopharyngeal viral nucleic acid swab and blood culture were negative, and chest x-ray showed no infiltrates. Ceftriaxone and pain medications were administered, and she was hospitalized.

Following admission, she had nausea, persistent fever, right upper quadrant (RUQ) pain, and developed dark urine. By day 3 , her liver edge was tender and palpable $2-3 \mathrm{~cm}$ below the right costal margin, and progressive anemia (Hb $8.9 \mathrm{~g} / \mathrm{dL}$ ) and thrombocytopenia (platelet count $67 \times 10^{9} / \mathrm{L}$ ) were evident (Fig 1 ). Hepatic ultrasound showed moderate hepatomegaly with an echogenic liver but no thrombosis. Laboratory testing showed elevated serum levels of $\gamma$-glutamyltransferase $(\gamma \mathrm{GT}, 155 \mathrm{U} / \mathrm{L})$, total bilirubin $(11.8 \mathrm{mg} / \mathrm{dL})$, conjugated bilirubin $(6.8 \mathrm{mg} / \mathrm{dL}$ ), alanine transaminase (ALT, $781 \mathrm{U} / \mathrm{L})$, and aspartate transaminase (AST, 1360 $\mathrm{U} / \mathrm{L}$ ). Plasma fibrinogen and activated partial thromboplastin time (aPTT) were normal. Her prothrombin time/international normalized ratio (INR) was borderline elevated. Laboratory testing for hepatitis A/B/C infection was negative. Parvovirus polymerase chain reaction (PCR) and adenovirus PCR were negative. Cytomegalovirus IgG was positive but IgM was negative. Quantitative blood PCR assay for EBV DNA showed significant elevation at $7020 \mathrm{IU} / \mathrm{mL}$. 
The clinical picture was most consistent with hepatic sequestration triggered by EBV. To avoid the phenomenon of reverse sequestration, ${ }^{10}$ she received a simple transfusion of one unit of packed red blood cells with prompt and sustained improvement in her $\mathrm{Hb}$ level. Tests of liver function normalized by one week after hospital discharge.

\section{Patient 2}

A 16-year-old boy with HbSC disease, who had undergone splenectomy splenectomy at age 4 years after splenic sequestration, presented with fever, sore throat, fatigue, headache, and chest pain. There was no lymphadenopathy. WBC count was $13 \times 10^{3} / \mu \mathrm{L}$, with increased atypical lymphocytes $\left(1.1 \times 10^{3} / \mu \mathrm{L}\right), \mathrm{Hb}$ was $12.9 \mathrm{~g} / \mathrm{dL}$, and platelet count was $409 \times 10^{9} / \mathrm{L}$. Creatinine was elevated at $1.4 \mathrm{mg} / \mathrm{dL}$, possibly reflecting dehydration, but electrolytes were within normal limits. Liver function tests were not performed at that time. Nasopharyngeal viral nucleic acid swab and blood culture were negative, and chest x-ray showed clear lungs. He received ceftriaxone and intravenous fluids. His pain was controlled with oral analgesics, so he was discharged home.

He returned 2 days later with persistent fever and progressive lower back, chest, and upper abdominal pain. His WBC had increased to $26.3 \times 10^{3} / \mu \mathrm{L}$ with a persistent atypical lymphocytosis. Hb was $10.8 \mathrm{~g} / \mathrm{dL}$ and platelet count was $297 \times 10^{9} / \mathrm{L}$. Serum chemistries were notable for elevated bilirubin $(4.5 \mathrm{mg} / \mathrm{dL})$, ALT $(366 \mathrm{U} / \mathrm{L}), \mathrm{AST}(375 \mathrm{U} / \mathrm{L})$, and $\gamma \mathrm{GT}(74 \mathrm{U} / \mathrm{L})$. Creatinine was slightly lower than his previous visit at 1.04 $\mathrm{mg} / \mathrm{dL}$. Plasma lipase and amylase were normal. His chest x-ray remained clear, and abdominal ultrasound showed a normal gallbladder. He was admitted for intravenous analgesia and monitoring.

Over the next 12 hours, his pain intensified and his abdomen became distended. Hepatic ultrasound demonstrated hepatomegaly with low hepatic arterial velocity and resistive index, suggestive of sequestration. He developed hypoxemic respiratory failure and was intubated. Chest x-ray showed interval development of right hilar consolidation and basilar opacities. Serial laboratory tests demonstrated a progressive leukocytosis and marked increase in ALT and total bilirubin (Fig 1) consistent with acute hepatitis. Plasma ammonia was normal.

He underwent an automated red cell exchange on the first hospital day with goal $\mathrm{Hb} 10 \mathrm{~g} / \mathrm{dl}$ and $\mathrm{Hb} \mathrm{S}$ $<30 \%$. Shortly thereafter, he developed hypotension requiring vasopressors. He had hypocalcemia likely caused by inability to hepatically metabolize the citrate anticoagulation utilized in the erythrocytapheresis procedure. He developed laboratory evidence of coagulopathy ( $\mathrm{aPTT}=52 \mathrm{~s}$, INR $=2.3$ ) on day 3 , without clinical bleeding, that resolved over the ensuing week. He required continuous renal replacement therapy for acute kidney injury with creatinine $>5 \mathrm{mg} / \mathrm{dL}$ and circulatory overload. He received additional erythrocyte transfusions to maintain his $\mathrm{Hb}>8 \mathrm{~g} / \mathrm{dL}$.

His clinical course was consistent with intrahepatic cholestasis, a severe form of hepatopathy marked by liver synthetic dysfunction, coagulopathy and often multi-organ failure. ${ }^{1,5}$ He gradually improved and was extubated on day 9 but was persistently febrile, so he underwent an evaluation for infection. Cytomegalovirus IgM and IgG were negative. EBV viral capsid antigen (VCA) IgM and IgG were positive on day 10, suggesting that acute EBV infection incited his critical illness. Reinforcing this premise, a convalescent EBV VCA IgM drawn 5 months later was negative. A 6-month regimen of chronic transfusion therapy was administered to facilitate organ healing.

\section{Discussion}

The clinical entities represented under the rubric of sickle hepatopathy (Table 1) encompass a disease spectrum; clinical manifestations vary depending on the relative degrees of cell trapping, ischemia, and intracanalicular cholestasis. ${ }^{1-6}$ There is overlap among these entities, so precise classification is often challenging. Patient 1 had a clinical course best classified as hepatic sequestration, whereas Patient 2 experienced intrahepatic cholestasis with multi-organ failure. Although illness severity differed between the two patients, there were several common features: 1) both individuals were teenagers with $\mathrm{HbSC}$ disease and primary EBV infection, as evidenced by atypical lymphocytosis and positive EBV IgM or PCR, 2) symptoms were 
initially attributed to sickle cell-related pain rather than infectious mononucleosis, 3) hepatomegaly, anemia, and thrombocytopenia progressed rapidly, 4) erythrocyte transfusions were required, 5) there was marked elevation of serum transaminases and bilirubin, and 6) a reactive thrombocytosis was noted during the recovery phase (Fig 1).

We surmise that EBV infection triggered sickle hepatopathy in these two cases. EBV-induced sickle hepatopathy has not been reported previously. EBV is known to cause acute hepatitis, although the degree of elevation of serum ALT or bilirubin is typically mild. ${ }^{11-13}$ Occasionally EBV results in overt cholestatic hepatitis, ${ }^{14-20}$ and there is one noteworthy report of a 15-year-old with HbSC disease who developed EBVinduced cholestatic hepatitis without sickle hepatopathy (maximum serum ALT and total bilirubin of 770 $\mathrm{U} / \mathrm{L}$ and $12.5 \mathrm{mg} / \mathrm{dL}$, respectively). ${ }^{21}$ We posit that the marked serum ALT elevation seen in Patient 1, which is not typical of hepatic sequestration crisis (Table 1), partly reflected EBV-induced hepatitis.

\section{Conflict of Interest}

The authors have no conflicts of interest to declare.

\section{Acknowledgments :}

We thank the patients and their families.

\section{References}

1. Allali S, Montalembert MD, Brousse V, et al. Hepatobiliary complications in children with sickle cell disease: a retrospective review of medical records from 616 patients. J Clin Med . 2019;8(9):1481-1481. doi:10.3390/jcm8091481.

2. Shah R, Taborda C, Chawla S. Acute and chronic hepatobiliary manifestations of sickle cell disease: a review. World J Gastrointest Pathophysiol . 2017;8(3):108-116. doi:10.4291/wjgp.v8.i3.108.

3. Ahn H, Li C, Wang W. Sickle cell hepatopathy: clinical presentation, treatment, and outcome in pediatric and adult patients. Pediatr Blood Cancer . 2005;45(2):184-190. doi:10.1002/pbc.20317.

4. Pecker LH, Patel N, Creary S, et al. Diverse manifestations of acute sickle cell hepatopathy in pediatric patients with sickle cell disease: a case series. Pediatr Blood Cancer . 2018;65(8):e27060. doi: $10.1002 /$ pbc. 27060 .

5.Banerjee S, Owen C, Chopra S. Sickle cell hepatopathy.Hepatology. 2001;33(5):1021-1028. doi:10.1053/jhep.2001.24114.

6. Buchanan GR, Glader BE. Benign course of extreme hyperbilirubinemia in sickle cell anemia: analysis of six cases. J Pediatr. Jul 1977;91(1):21-4. doi:10.1016/s0022-3476(77)80436-8.

7. Gardner K, Suddle A, Kane P, et al. How we treat sickle hepatopathy and liver transplantation in adults. Blood . 2014;123(15):2302-2307. doi:10.1182/blood-2013-12-542076.

8. Ahmed N, Chizhevsky V. Acute hepatic sequestration associated with pneumococcal infection in a 5year-old boy with sickle $\beta^{0}$-thalassemia: a case report and review of the literature. J Pediatr Hematol Oncol . 2007;29(10):720-724. doi:10.1097/MPH.0b013e31814d6866.

9.Tsunoda $\mathrm{T}$, Inui A, Iwasawa $\mathrm{K}$, et al. Acute liver dysfunction not resulting from hepatitis virus in immunocompetent children.Pediatr Int . 2017;59(5):551-556. doi:10.1111/ped.13249.

10. Lee ES, Chu PC. Reverse sequestration in a case of sickle crisis.Postgrad Med $J$. Aug 1996;72(850):487-8. doi:10.1136/pgmj.72.850.487.

11. Leonardsson H, Löve A, Björnsson ES, Hreinsson JP. Hepatitis due to Epstein-Barr virus and cytomegalovirus: clinical features and outcomes.. Scand J Gastroenterol . 2017;52(8):893-897. doi:10.1080/00365521.2017.1319972. 
12. Crum NF. Epstein Barr virus hepatitis: case series and review.South Med J. 2006;99(5):544-548.

13. Drebber U, Kasper HU, Krupacz J, et al. The role of Epstein-Barr virus in acute and chronic hepatitis. J Hepatol . 2006;44(5):879-885. doi:10.1016/j.jhep.2006.02.006.

14. Massei F, Palla G, Ughi C, Macchia P, Maggiore G. Cholestasis as a presenting feature of acute EpsteinBarr virus infection. Pediatr Infect Dis J . 2001;20(7):721-722. doi:10.1097/00006454-200107000-00020.

15. Bernstein CN, Minuk GY. Infectious mononucleosis presenting with cholestatic liver disease. Ann Intern Med . 1998;128(6):509.

16. Barlow G, Kilding R, Green ST. Epstein-Barr virus infection mimicking extrahepatic biliary obstruction. J R Soc Med . 2000;93(6):316-318. doi:10.1177/014107680009300612.

17. Kang MJ, Kim TH, Shim KN, et al. Infectious mononucleosis hepatitis in young adults: two case reports. Korean J Intern Med . 2009;24(4):381-387. doi:10.3904/kjim.2009.24.4.381.

18. Edoute Y, Lachter J, Furman E, Baruch Y, Assy N, Bassan L. Case report: severe cholestatic jaundice induced by Epstein-Barr virus infection in the elderly. JGH Open. 1998;13(8):821-824. doi:10.1111/j.14401746.1998.tb00739.x.

19.Canović P, Gajović O, Todorović Z, Mijailović Z. Epstein-Barr virus hepatitis associated with icterus - a case report. Med Pregl . 2006;59(3-4):179-182. doi:10.2298/MPNS0604179C.

20. Pagidipati N, Obstein KL, Rucker-Schmidt R, Odze RD, Thompson CC. Acute hepatitis due to EpsteinBarr virus in an immunocompetent patient. Dig Dis Sci. 2010;55:1182-1185. doi:10.1007/s10620-009-0835-z.

21.Black TP, Rao A. Epstein Barr virus induced cholestatic hepatitis in a patient with hemoglobin SC disease. American Journal of Case Reports . 2011;12:58-61. doi:10.12659/AJCR.881780.

TABLE 1. Spectrum of acute sickle cell hepatopathy in childhood

${ }^{1}$ Adapted from Shah et al. , Banerjee et al., and Buchanan \& Glader. Abbreviations: ALT, alanine transaminase; AST, aspartate transaminase; RUQ, right upper quadrant.

FIGURE 1. Laboratory values versus time since hospital admission for two patients with EBV-induced sickle hepatopathy. Abbreviations: ALT, serum alanine transaminase; CR, serum creatinine; CRRT, continuous renal replacement therapy; Hb, hemoglobin; PLT, platelet count; T. BILI, serum total bilirubin; Txn, transfusion (erythrocytes).

\section{Hosted file}

EBV Table 1.pdf available at https://authorea.com/users/395302/articles/508604-epstein-barrvirus-induced-sickle-hepatopathy 

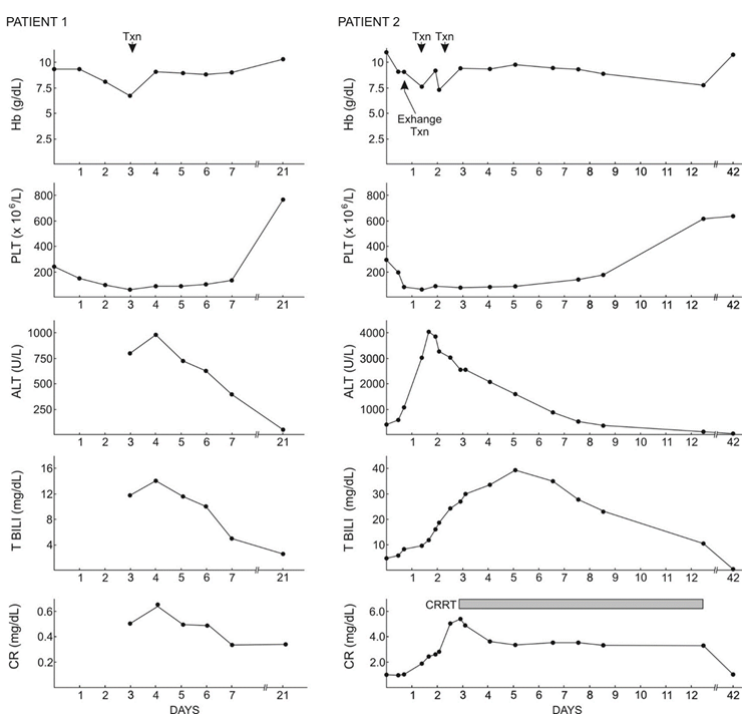